\title{
LONG-TERM RESULTS FOR SIMULTANEOUS SURGICAL TREATMENT OF GLAUCOMA COMBINED WITH CATARACT USING THE SUPRACHOROIDAL AUTOSCLERAL DRAINAGE METHOD
}

\section{Mikhail Frolov' , Alexander Frolov ${ }^{1,2}$, Ksenia Kazakova ${ }^{1,3}$, Jonas Atulebire Akambase}

${ }^{1}$ Department of Ophthalmology, RUDN University, 26, Bakinskaya str., Moscow, 115516, Russian Federation;

${ }^{2}$ State Budgetary Institution of Health Care "V. M. Buyanov city clinical hospital" of Moscow Department of health, 26, Bakinskaya str., Moscow, 115516, Russian Federation

${ }^{3}$ Diversified medical holding "SM-clinic", 8, Yartsevskaya str., Moscow, 121351, Russian Federation

A BSTRACT - The development of cataract in patients with glaucoma poses an important task for ophthalmologist to sought pathogenetic feasible and effective treatment of this combined pathology. This is due to the fact that glaucoma and cataract are one of the main causes of blindness and low vision [1].

In comparison with traditional methods, sutureless cataract surgery and new methods for anti-glaucoma operations are widely used in clinical practice due to their high records of safety. The latter has led to an increasing use of combined treatment for patients with combined pathology among the population [2]. The combined operation allows normalization of ophthalmotonus and restore visual functions, which is exceedingly important in reducing the amount of time required for visual, professional and social rehabilitation [3].

The utilization of drains in ophthalmic surgery is the most relevant and propitious direction in ophthalmic surgery, in view of the fact that they cause a longer and stable hypotensive effect. Currently, methods of activation of the uveoscleral outflow pathway by introducing drains from different materials into the suprachoroidal space, as well as a combination of operations aim at activating various aqueous humor outflow pathways [4]. The existence of numerous surgical aids (their modifications), various drains and drainage devices indicate that there is no universal surgical method for treatment of glaucoma [8].

Currently, the most promising methods are: (I) the activation of uveoscleral outflow pathway by introducing drains from different materials into the suprachoroidal space, and (II) the combination of operations aim at activating various aqueous humor outflow pathways [5].

\section{PURPOSE}

Evaluation of long-term functional results of combined surgical method for treatment of glaucoma in combination with cataract using the suprachoroidal autoscleral drainage.

\section{MATERIAL AND METHODS}

The study included 84 patients ( 84 eyes). Out of the 84 patients 61 were women and $23-$ men. The observation period lasted from March 2018 to January 2019. The mean preoperative intraocular pressure (IOP) was $31.4 \pm 1.3 \mathrm{mmHg}$. Assessment of ophthalmic status included conventional clinical examination: determination of visual acuity, tonometry, biomicroscopy, ophthalmoscopy, keratorefractive, and perimetry. All patients in the preoperative and postoperative period underwent applanation tonometry by A.N. Maklakov, with a weight of 10.0 grams. The B.L Polyaka's ruler was used for calculation. The state of the uveoscleral outflow pathways activated by autoscleral drainage of the suprachoroidal space after impenetrable deep sclerectomy in combination with cataract was assessed using an optical coherence tomography (OCT) on the Zeiss Visante OCT device (Germany).

The indication for carrying out non-penetrating deep sclerectomy with drainage of suprachoroidal space autoclaves with cataract phacoemulsification of complicated cataract was combined with uncompensated (b-c) glaucoma stage II-III.

\section{OPERATION TECHNIOUE}

The surgical treatment was carried out as follow: From the limb make a $5 \mathrm{~mm}$ incision of the conjunctiva from 10 to $1 \mathrm{~h}$. Separate the conjunctiva and the tenon's capsule from the sclera, from the limb. Coagulate the sclera vessels. With the help of a scleral knife cut out a rectangular scleral flap base to the limb on $2 \backslash 3$ sclera thickness, size $3 \times 4$. Furthermore, on the surface of the remaining $1 \backslash 3$ of the 
sclera, longitudinal and parallel incisions are made to form four (4) strips of length and width, $4 \mathrm{~mm}$ and $1 \mathrm{~mm}$ respectively. Cut the distal strip up to the flat part of the ciliary body. With a spatula make a tunnel (width $-2 \mathrm{~mm}$ and length $-4 \mathrm{~mm}$ ) into the suprachoroidal space, where the previously separated distal sclera strip leads to a depth of $3.5 \mathrm{~mm}$. Thus, the self-drainage in this method is the patient's own sclera. Of the remaining three scleral strips, the median is separated completely, exposing the surface of the ciliary body. Further, in the drainage system of the anterior chamber angle of the eye, the outer wall of the Schlemm's canal is excised, the corneal tissue is also excised $2.0 \mathrm{~mm}$ above the sinus, using iris forceps remove the pigment epithelium from the inner wall of the Schlemm's canal, where further filtration of the intraocular fluid from the anterior chamber will occur, creating a filtration zone. Subsequently, cataract extraction is performed by standard phacoemulsification with intraocular lens implantation. Corneal incision $2.2 \mathrm{~mm}$. Rectangular flap sutured with two nodal sutures. A continuous suture is performed over the conjunctiva.

\section{RESULTS}

\section{AND DISCUSSION}

Complications were not recorded in the intraoperative and the early postoperative period of the operation. In all cases, mild inflammatory reaction was recorded, as well as first degree mild inflammatory reaction, according to the classification of $S$. N. Fedorov - E. V. Egorova [9]. When all patients were examined after 6 months, parameters such as intraocular pressure (IOP) remained within the statistical norm. In the late postoperative period (1.5 years), the patients with normotony (mean IOP, 16.0 $\pm 1.8 \mathrm{~mm} \mathrm{Hg}$ ) were 69 in total. In 15 cases, there was an increase in IOP, for which hypotensive therapy ( $\beta$-blockers) was prescribed. In the evaluation of OCT data, preservation and increase in size of the uveoscleral slit with a functioning filtration zone was observed.

Currently, there is no single approach on the tactics of managing patients with primary open-angle glaucoma combined with cataract, although there are quite a lot of works that give preference to simultaneous cataract extraction and anti-glaucoma surgery in recent literatures [6]. The main requirements that apply to the anti-glaucoma component in combined operations are a long hypotensive effect and stabilization of the glaucoma process and maximum safety of the intervention. One possible solution to this problem could be operations aim at activating uveoscleral outflow, which normally provides evacuation of $4-27 \%$ of fluid [7].

\section{CONCLUSION}

We conclude that since it is a one-stage surgery, it could be advantageous in reducing a patient's length of stay in the hospital and also solving economic, social, moral, psychological, and financial issues. Our proposed method is less traumatic, safe, contributes to the stabilization of intraocular pressure, and does not require the use of donor materials, including xenotransplantation. This type of surgery can be performed at any stage of glaucoma.

\section{REFERENCES}

1. Katibeh M, Pakravan M, Yaseri M, Pakbin M, Soleimanizad R. Prevalence and Causes of Visual Impairment and Blindness in Central Iran; The Yazd Eye Study. J Ophthalmic Vis Res. 2015 JulSep;10(3):279-85. doi: 10.4103/2008-322X.170362. PubMed PMID: 26730314; PubMed Central PMCID: PMC4687262.

2. Erichev V. P., Abdulkadyrova, M. D., The IMMORTAL A. M., Kalinin O. M. the Main directions of modern medical and surgical treatment of primary glaucoma: Handbook for physicians. - M., 2000. P. 26. [n Russian].

3. ERICHEV V. P. The main directions of surgical treatment of glaucoma. //Glaucoma. Materials of the allRussian scientific and practical conference "Glaucoma at the turn of the Millennium: results and prospects". M., 1999. P. 171-174. [In Russian].

4. Puchkov S. G. Surgical treatment of combinations of glaucoma and cataract with artificial lens implantation: Method. Recommendations. M.: Moscow health of the RSFSR. M. B. I.; 1991. P. 19. [In Russian].

5. Alekseev B. N., Brewers H. H., Kabanov, I. B. Modification of the operation of depressing the sclera in the treatment of end-stage glaucoma. // Westn. ophthalmologies. - 1986. No. 2. P. 13-16. [In Russian].

6. Mermoud A, Schnyder C.C. Nonpenetrating filtering surgery in glaucoma //Current Opinion in Ophthalmology. - 2000 - No. 11. - P. 151-157. DOI: 10.1097/00055735-200004000-00015

7. Bhola R.M., Prasad S., McCormic A.G. et al. Pupillary distorsion and staphyloma following transscleral contact diode laser cyclophotocoagulation: a clinicopathological study of three patients. // Eye. 2001. Vol. 15. - No. 4. - P. 453-457. DOI: $10.1038 /$ eye. 2001.154

8. Frolov M. A., Fedorov A. A., Nazarova S. V., Gonchar P. A., Kumar Vinod, Frolov A. M. Morphological condition of allodrainage, implanta- 
tion on the basis of refractory glaucoma, long-term monitoring. Ophthalmology. 2009; 6 (3): 11-14. [In Russian].

9. Fedorov S. N., Egorova E. V. Errors and complications in the implantation of an artificial lens. M.: Medicine, 1993. P. 243. [In Russian]. 